\title{
Proceeding
}

Supplementary Issue: Summer Conferences of Sports Science. Costa Blanca Sports Science Events, 25-26 September 2020. Alicante, Spain.

\section{The predictive value of high jump achievement in terms of some physical abilities and biomechanical variables for young youth}

\author{
MAHDI LAFTA RAHI ${ }^{1}$, ALI HUSSEIN SAGHEER ${ }^{2}$ \\ ${ }^{1}$ College of Physical Education and Sport Science, Waist University, Iraq \\ ${ }^{2}$ Faculty of Science, Waist University, Iraq
}

\begin{abstract}
The development of the athletic activity including high jump, was not just a coincidence, but it has gone through many stages of development until it reached the current stage. What makes the high jump activity different from other athletic activity is that it is characterized by the heights altitude a jumper can reach. Therefore, prediction plays a key role in knowing the athlete future achievement results by inferring known facts and data that helps trainers guide and plan training programs and codify their content towards identifying and applying variables that have an effective impact on the training process, raising the athlete skills and physical level. To allow the athlete to reach his/her best performance and jump as high as he could. On this basis, the importance of the research lies in predicting the level of achievement for high jump athletes based on the results of some physical abilities and biomechanical variables related to the athlete performance through the use of the predictive equation proposed by the researcher.

Keywords: High jump; Physical abilities; Biomechanical variables.
\end{abstract}

\section{Cite this article as:}

Rahi, M.L., \& Sagheer, A.H. (2020). The predictive value of high jump achievement in terms of some physical abilities and biomechanical variables for young youth. Journal of Human Sport and Exercise, 15(4proc), S1035-S1045. doi:https://doi.org/10.14198/jhse.2020.15.Proc4.06

Corresponding author. College of Physical Education and Sport Science, Waist University, Iraq.

E-mail: dr.ghafarsaeedissa@gmail.com

Abstract submitted to: Spring Conferences of Sports Science. Costa Blanca Sports Science Events, 19-20 June 2020. Alicante, Spain.

JOURNAL OF HUMAN SPORT \& EXERCISE ISSN 1988-5202

(c) Faculty of Education. University of Alicante

doi:10.14198/jhse.2020.15.Proc4.06 


\section{INTRODUCTION}

The development in achieving achievements and records of all sport games and events in international forums and tournaments is a sure outcome of all the scientific efforts and experiences that have been made in the field of training methods and techniques as well as the effective contribution of other sciences in supporting achievement in sport.

Athletics competitions are among the activities that are characterized by a high degree of excitement and suspense, due to the creativity and distinction in the performance of its various activities, which require continuous communication in training programs and the use of various modern training techniques, which focused on the main and influential variables to reach the higher levels of achievement.

The development witnessed by athletics activities, including the high jump event, was not a mere coincidence, rather it went through many stages of development until it reached the stage that we use and we observe at the present time, as these developments aimed to raise the digital level (achievement) and technical performance to reach the best methods of mechanical aspects to jump without these methods contradicting the contest law.

The method of performance in the high jump is distinguished from other activities by obtaining the highest altitude distance of the jumper's body without relying on any tool to help it to rise, which required those in charge of the training process to be familiar with the rules of kinetic analysis and to know the mechanism of technical performance involved in producing the kinetic energy that achieves the highest Completion (Karim, \& Al-Mafraji, 2010).

Prediction leads a major role in knowing the results of future achievement by inferring from known facts and data that help trainers in directing and planning training programs and codifying their content towards identifying and applying effective variables in the training process, raising the physical and skill level, and achieving high achievement for young hoppers (Gneiting, \& Katzfuss, 2014).

Prediction in the sport field is an important topic, as it contributes to setting expectations and perceptions about the reality of the athlete's situation and gives an indication of the level of progress and development through several data that must be available to the coach or researcher, which are the basis for this expectation.

On this basis, the importance of research appears in predicting the level of achievement of high jump contestants depending on the results of tests of some physical abilities, the biomechanical variables of performance, through which it is possible to know the level that the hopper will achieve, as well as the need to address weaknesses and strengthen strengths by emphasizing the investment of training techniques and motor analysis in young hoppers, to reach them to the best sports levels, in pursuit of distinguished achievement in this event.

\section{The research problem}

Through our review of many studies, sources, and scientific references, as well as our follow-up of the levels of achievement of the Iraqi youth team of the high jump events we did not find an accurate technical arithmetic method for predicting the achievement of the hoppers, and in the sense of facilitating the work of trainers and in order to save efforts and time in knowing the jumpers level in the future by designing a statistical equation 
and time in knowing the level of the jumpers in the future by designing a statistical equation to figure out the predictive value of the level of achievement of the young jumpers in the future in the high jump events.

\section{The research goals}

The research aims to

Finding a predictive equation for the achievement of the high jump in the sense of some physical abilities and biomechanical variables for young hoppers.

The research impose

The value of the achievement of the high jump for youth can be predicted in terms of some physical abilities and biomechanical variables through the proposed equation.

The research fields

- Human field: Players of the national youth team in the high jump event.

- Temporal field: from 25-11-2019 to 15-7-2020.

- Spatial field: The National centre for athletic talent development for athletics in Baghdad.

\section{MATERIAL AND METHODS}

\section{Procedures}

The researcher used the descriptive approach in the manner of interrelationships due to its suitability to the nature of the problem.

\section{Participants}

The study community was represented by the players of the Iraqi youth team in high jump and they represent the study sample by (7) contestants for the sport season 2019-2020.

\section{Measures}

The methods for collecting the information are the following (observation, tests, a camera with a speed of (500) images / sec (3), a scale, a stopwatch, a laptop, a tape measure, a medical scale, foot scan.

\section{Analysis}

The researcher used the statistical bag (SPSS) to find the appropriate statistical treatments for the study.

\section{FIELD RESEARCH PROCEDURES}

\section{Determine physical abilities and tests for each ability}

After reviewing previous studies with specialization close to the current study and recent scientific sources in sports training and tests, the researcher identified the physical abilities and tests for each of the abilities identified and these abilities (the explosive power of the two legs, the maximum strength of each leg, the rapid strength of the torso and the abdominal muscles). In order to obtain the necessary data for the nature of statistical laws in line with the number of studies samples, the researcher took data (3) attempts for each test, as well as the attempts to achieve the high jump.

The vertical jump up with foot scan device (Majed, 2016).

The purpose of the test:

To measure the vertical explosive force of the leg muscles. 
Tools used:

Foot scan platform, calculator.

Performance description:

The player stands on a strength measurement platform, the feet are parallel and open to the breadth of the pelvis, and from Half knee bent mode he swings his arms backward then in front and then the jump as far as possible

Registration:

Each athlete is given three tries, and 30-sec rest between each attempt and other, scoring the highest power ever recorded by the player.

Maximum strength

Tested as follows:

- $\quad$ Leg push test (Al-Fadhli, 2010):

The purpose of the test

To measure the maximum strength of the two legs.

Tools used:

LEG-SLED-602 is equipped with a wheelchair without a seat with shoulder and head cushions, with a ground on which the legs are based, and the seat of the device is horizontally moving attached to a wire and rollers and pulsating with weights up to $300 \mathrm{~kg}$.

Performance description:

The tester lies on his back, relying on the device's cushions on his shoulders, then we determine the distance of the knees through a lever that controls the extension of the angle of the knees, resting between 30 seconds after each attempt.

\section{Record}

The athlete's ability to measure the maximum strength of the two legs is determined by pushing the greatest resistance $(\mathrm{kg})$.

Rapid force

The test was as follows:

- Torso bending test from a seated position (Galeriek, 2015).

Purpose of the test:

To measure the rapid strength of the abdominal muscles.

Tools used:

Flat-ROL device can measure the rapid strength of the torso and abdomen, this device works in two directions separately, as the device consists of weights that can be changed by a spring (nail) and a seat measuring $(40 \times 40) \mathrm{cm}$ with a footrest on it and a handle on the other side with a lever arm connected to half a pulley and a wire attached to weights. 
Performance description:

The tester sits on the seat and puts the arm of the device in front of his chest, and puts the feet in the cushions so as not to participate in the performance and its work is only support, the tester works to push the arm of the device forward by the chest at maximum weight rate (resistance). Each athlete is given a 60 -second break between the two attempts.

The maximum strength of each leg

The test was as follows:

- One leg push test (Galerik, 2015):

Purpose of the test:

To measure the maximum strength of each leg.

Tools used:

LEG-PRESS consists of a wheelchair for pulley angle control and consists of two-foot rests, the tester can use both legs and one leg, with weight straps for each armrest carrying up to $500 \mathrm{~kg}$.

Performance description:

The tester sits on the wheelchair and puts one of the feet to measure its maximum strength, as he pushes the footrest forward taking into account that the torso in this process is not involved, knowing that there is no grip of the arms for the purpose of engaging the upper part. The tester is given three attempts to choose the best try, resting between $30 \mathrm{sec}$ per attempts.

Record:

The athlete's ability to measure the maximum strength of each leg is determined by the force of the greatest resistance $(\mathrm{kg})$.

Rapid strength

The test was as follows:

- $\quad$ Torso Lift Test (Karim, \& Al-Mafraji, 2010):

Purpose of the test:

To measure the rapid strength of the torso.

Tool used:

FLAT-ROL can measure the rapid strength of the torso and abdomen, this device works in two directions separately, as the device consists of weights that can be changed by means of a spring (nail) and a seat measuring $(40 \times 40) \mathrm{cm}$ with an armrest to put the feet on it and a handle on the other side with a lever attached to a half-pulley and a wire attached to a weight.

Performance description:

The tester sits behind the seat and places the arm of the device behind his back, as the footrest is changed each according to the length of the legs and the more the legs are pushed apart, the less they are involved in the work and its work is only to support.

The tester pushes the arm of the device back with the torso at maximum weight (resistance). Each athlete is given a 60 -second break between the two attempts. 
Record:

Choosing the best attempt in which the most repetitions are recorded for the laboratory within 30 seconds.

- The high jump achievement test:

Purpose of the test:

Measuring the achievement for each contestant.

Tool used:

Legal high jump device, tape measure, registration forms, camera.

Performance description:

Each member of the sample performs the high jump test according to the technical stages of the performance, and the performance is in accordance with the conditions of the IAAF in the effectiveness of the high jump in the execution of attempts. With the placement of three cameras distributed in special places for the process of performance analysis.

Record:

Each hopper is given three attempts at each height, and the attempt with which the highest height was achieved is recorded for him.

\section{Exploratory experience}

The researcher conducted the exploratory experiment on a sample consisting of (3) hoppers on Tuesday 26/11/2019 at the Sports Talent Center for Athletic Games in Baghdad.

The exploratory experience has benefited the researcher in identifying the validity of tests and measures used to collect study data.

Main experience

The researcher applied the study tests and achievement on the sample of the study, which consisted of (7) hoppers namely the Iraqi youth team in the high jump, on Saturday 4/12/2019 at the Sports Talent Care Center for Athletics in Baghdad.

\section{RESULTS}

\section{Statistical description of the distributions of research variables for the model building sample}

Table 1. Arithmetic means, standard deviations, and the value of Shapiro-Wilk test. For the model-building sample in the researched variables.

\begin{tabular}{|c|c|c|c|c|c|}
\hline \multirow{2}{*}{ Variables } & \multirow{2}{*}{ Tests } & \multirow{2}{*}{ S- } & \multirow{2}{*}{$\mathbf{P}$} & \multicolumn{2}{|c|}{ Shapiro-Wilk test } \\
\hline & & & & Calculated & Significance \\
\hline \multirow{7}{*}{ 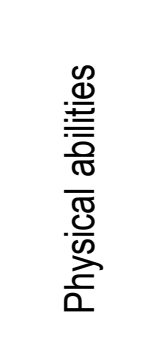 } & Accomplishment & 1.896 & 0.078 & 0.834 & .227 \\
\hline & Jumping explosive force & 1573.433 & 61.131 & 0.306 & .143 \\
\hline & Legs strength & 177.071 & 7.280 & 0.927 & .182 \\
\hline & Maximum right leg power & 136.000 & 3.258 & 0.985 & .912 \\
\hline & Maximum left leg power & 167.429 & 5.019 & 0.954 & .441 \\
\hline & Torso Side-bending in Sitting & 36.571 & 3.877 & 0.968 & .670 \\
\hline & Torso lift & 39.143 & 2.685 & 0.990 & .167 \\
\hline S1040 & | 2020 | Proc4 | VOLUME 15 & & & (c) 2020 & ity of Alicante \\
\hline
\end{tabular}




\begin{tabular}{|c|c|c|c|c|c|}
\hline \multirow{6}{*}{ 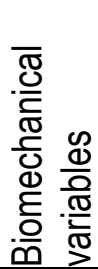 } & The highest power achieved when rising & 1992.546 & 8.536 & 0.989 & .742 \\
\hline & Momentary push time to rise & 0.266 & 0.165 & 0.965 & .610 \\
\hline & Launch speed & 4.640 & 0.740 & 0.312 & .120 \\
\hline & Launch angle & 46.357 & 4.830 & 0.988 & .939 \\
\hline & Body rotation angular velocity & 226.750 & 10.930 & 0.964 & .593 \\
\hline & Arc speed rate & 6.223 & 0.578 & 0.901 & .070 \\
\hline
\end{tabular}

The results of Table 1 indicate the good prevalence of model-building sample scores at each of the research variables (physical, biomechanical), as the significance level values associated with the calculated values of (Shapiro) test, which all came greater than the significance level value (.05), indicated that all the variables Have achieved the equinox curve.

- Building a prediction model for high jump achievement in terms of (physical capabilities and biomechanical variables) and (high jump achievement):

- Finding the correlation between (physical abilities and biomechanical variables) and (high jump achievement) among the model sample members:

Table 2. Correlation coefficient Values between (physical abilities and biomechanical variables) and (high jump accomplishment) for the researched sample.

\begin{tabular}{|c|c|c|c|c|c|}
\hline \multirow{2}{*}{\multicolumn{2}{|c|}{ Variables }} & \multirow{2}{*}{$\begin{array}{l}\text { Correlation } \\
\text { nature }\end{array}$} & \multicolumn{2}{|c|}{ Correlation coefficient } & \multirow{2}{*}{$\begin{array}{l}\text { Statistical } \\
\text { significance }\end{array}$} \\
\hline & & & Calculated & $\begin{array}{l}\text { Significance } \\
\text { level }\end{array}$ & \\
\hline \multirow{6}{*}{ 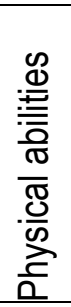 } & Jumping explosive force & Simple & 0.942 & .000 & Significant \\
\hline & Legs strength & Simple & 0.810 & .000 & Significant \\
\hline & Maximum right leg power & Simple & 0.834 & .000 & Significant \\
\hline & Maximum left leg power & Simple & 0.874 & .000 & Significant \\
\hline & Torso Side-bending in Sitting & Simple & 0.791 & .000 & Significant \\
\hline & Torso lift & Simple & 0.953 & .000 & Significant \\
\hline \multirow{6}{*}{ 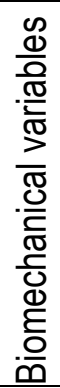 } & $\begin{array}{l}\text { The highest power achieved } \\
\text { when rising }\end{array}$ & Simple & 0.925 & .000 & Significant \\
\hline & Momentary push time to rise & Simple & 0.181 & .535 & Non-Significant \\
\hline & Launch speed & Simple & 0.838 & .000 & Significant \\
\hline & Launch angle & Simple & 0.201 & .491 & Non- Significant \\
\hline & $\begin{array}{l}\text { Body rotation angular } \\
\text { velocity }\end{array}$ & Simple & 0.835 & .000 & Significant \\
\hline & Arc speed rate & Simple & 0.825 & .000 & Significant \\
\hline
\end{tabular}

When reviewing the results of Table 2, we find that the values of the correlation coefficient between the variable (achievement of the high jump) and the physical capabilities (Explosive power by jumping up, thrust of the legs, the maximum strength of the right leg, the maximum strength of the left leg, bending the torso from sitting, lifting the torso) and the values of the correlation coefficient between the variable (high jump achievement) and the biomechanical variables (the highest force exerted during rise ,velocity of cruising, angular velocity of body rotation, average arc velocity) is significant because the significance level value associated with it were greater than the indication level value of (.05), which indicates that the connection is not intangible, the relationship is not real, and it was the result of chance. 


\section{Extracting indicators of the linear regression equation model}

In order to evaluate the model's accuracy of the result in the model building sample, the researcher resorted to the multiple correlation between the predictive variables and the outcome, whose results appear in Table 3.

Table 3. Quality indicators of the linear regression equation model.

\begin{tabular}{|c|c|c|c|}
\hline Variables & & Coefficient & Contribution \\
\hline Predictive & Accomplishment & factor $\mathbf{R}$ & ratio $R^{2}$ \\
\hline $\begin{array}{l}\text { Physical abilities (Jumping explosive force, Legs } \\
\text { strength, Maximum right leg power, Maximum } \\
\text { left leg power, Torso Side-bending in Sitting, } \\
\text { Torso lift). } \\
\text { Biomechanical variables (The highest power, } \\
\text { achieved when rising, Momentary push time to } \\
\text { rise, launch speed, Launch angle, Body rotation } \\
\text { angular velocity, Arc speed rate). }\end{array}$ & $\begin{array}{l}\text { High jump } \\
\text { Accomplishment }\end{array}$ & 0.996 & 0.992 \\
\hline
\end{tabular}

It appears from Table 3 that the value of the multiple correlation coefficient came in the amount of $(0.996)$ and that the value of the interpretation coefficient (the contribution rate) reached (0.992), which means that these variables explain a percentage of $(99.2 \%)$ of the achievement of the high jump.

Table 4. Shows the calculated test value (f), and the value of the accompanying significance level.

\begin{tabular}{lllllll}
\hline Variance Source & $\begin{array}{l}\text { Total } \\
\text { squares }\end{array}$ & $\begin{array}{l}\text { Freedom } \\
\text { level }\end{array}$ & $\begin{array}{l}\text { Average } \\
\text { squares }\end{array}$ & $\begin{array}{l}\text { Calculated } \\
\text { squalue }\end{array}$ & $\begin{array}{l}\text { Significance } \\
\text { level }\end{array}$ & $\begin{array}{l}\text { Statistical } \\
\text { significance }\end{array}$ \\
\hline Between groups & 0.078 & 10 & 0.008 & & & \\
Inside groups & 0.001 & 3 & 0.000 & 35.688 & .007 & Significant \\
Overall & 0.079 & 13 & & & & \\
\hline
\end{tabular}

Table 4 indicates that the value of the significance level associated with the (f) value was $(.007)$ and is smaller than the value of the indicative level (.05), which demonstrates the significance of the multiple linear regression model, and therefore the model represents the relationship between the variables in question the best representation.

Extracting the values of the regression equation coefficients (model)

Table 5. Values for regression equation coefficients and the significance of the model parameters.

\begin{tabular}{|c|c|c|c|c|c|c|c|}
\hline & & Param & ters & & & Value & \\
\hline Coeffici & & $\begin{array}{l}\text { The coe } \\
\text { equation }\end{array}$ & icient val & e of the & Calculated & Significance & Statistical \\
\hline nature & & $\begin{array}{l}\text { Non- } \\
\text { standard }\end{array}$ & $\begin{array}{l}\text { Standard } \\
\text { error }\end{array}$ & $\begin{array}{l}\text { Standard } \\
\text { (beta) }\end{array}$ & Caiculated & level & \\
\hline & A & 8.263- & 4.175 & & $3.979-$ & .002 & Significant \\
\hline $\begin{array}{l}\text { FIXed } \\
\text { amount }\end{array}$ & B1 & 0.00015 & 0.000 & 0.510 & 4.315- & .002 & Significant \\
\hline & B2 & 0.0031 & 0.002 & 0.286 & 2.348 & .040 & Significant \\
\hline
\end{tabular}




\begin{tabular}{|c|c|c|c|c|c|c|}
\hline B3 & 0.012 & 0.003 & 0.426 & 2.148 & .136 & $\begin{array}{l}\text { Non- } \\
\text { Significant }\end{array}$ \\
\hline B4 & 0.214 & 0.003 & $0.162-$ & 0.880 & .444 & $\begin{array}{l}\text { Non- } \\
\text { Significant }\end{array}$ \\
\hline B5 & 0.14 & 0.006 & 0.552 & 1.725 & .183 & $\begin{array}{l}\text { Non- } \\
\text { Significant }\end{array}$ \\
\hline B6 & 0.0051 & 0.007 & 0.521 & 3.264 & .009 & Significant \\
\hline B7 & 0.0043 & 0.002 & 0.475 & 3.827 & .005 & Significant \\
\hline B8 & 0.001 & 0.020 & $0.376-$ & $1.956-$ & .145 & $\begin{array}{l}\text { Non- } \\
\text { Significant }\end{array}$ \\
\hline B9 & 0.0025 & 0.002 & 0.357 & 2.520 & .026 & Significant \\
\hline B10 & 0.024 & 0.039 & $0.407-$ & $1.424-$ & .250 & $\begin{array}{l}\text { Non- } \\
\text { Significant }\end{array}$ \\
\hline
\end{tabular}

Table 5 indicates that the significance of the intercept coefficient (a) as well as the regression coefficients slope - (b1, b2, b6, b7, b9) as the values of the level of significance associated with the calculated (t) values came smaller than the level of significance (.05) This indicates the significance of these parameters for the multiple regression model.

The fixed magnitude indicates the relationship between the degree of achievement of the high jump and the predictive variables (physical abilities - biomechanical variables). Returning to the same table, we find that all the values of the significance level associated with the $(t)$ values calculated for the fixed magnitudes came smaller than the level of significance (.05), which means the predictive variables. It contributes effectively to the evaluation of outcome values.

From the above, the model will take the following form:

\section{The non-standard equation}

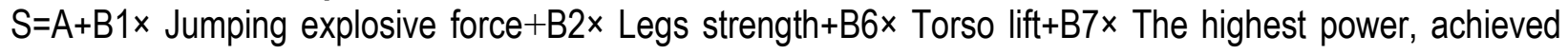
when rising $+\mathrm{B} 9 \times$ Body rotation angular velocity

\section{Standard equation}

$\mathrm{S}=\mathrm{A}+\mathrm{B} 1 \times$ Jumping explosive force $+\mathrm{B} 2 \times$ Legs strength $+\mathrm{B} 6 \times$ Torso lift $\times$ The highest power, achieved when rising $+\mathrm{B} 9 \times$ Body rotation angular velocity

\section{DISCUSSION}

By observing the results of Tables (3-4-5), it becomes evident that the contribution ratios for the physical abilities of the high jump hopper and the biomechanical variables came in different ways, and the results showed that the degrees of high contribution between the physical capabilities and the biomechanical variables with the hoppers achievement level formed the integrated picture of performance, it turns out through that, the explosive power of the two legs contributes to the completion of a momentary work when the hopper performs a rapid and explosive movement as in the stage of rising, where the description of the first movement of rising in the effectiveness of the high jump in the explosive movement, and this corresponds to what Mohammed Nasreddine Radwan stated that "this movement performs strongly and very quickly according to the goal of skill and the level of performance which depends mainly on the physical level of the athlete" (Radwan, 2002). 
And that the compatibility of high performance plays a major role through the work and consistency of physical abilities in accordance with the mechanical conditions of the high jump effectiveness, as the force exerted by the jumper during the rising process contributes and secures the process of proper linkage with the moment of advancement to get the best vertical height (Tidow, 1993).

As we know, there are two key factors to be observed in the rising, namely, to get the greatest vertical velocity possible for the centre of the body's weight and to create an angled velocity of sufficient rotation around this centre to pass the crossbar.

Dapena also states that the direction of the ground reaction force up vertically basically creates the angular thrust at the angular velocity needed for the jumper's body to cross the beam (Dapena, 2000).

The researcher focused on the most important physical abilities and the biomechanical variables that are most related and contributed to the achievement of the high jump by designing the predictive equation after applying a set of statistical equations that deal with achieving the goal of the study, which stipulates finding a predictive equation to achieve the high jump in terms of some of the physical abilities and biomechanical variables of the young jumpers in which we see a service for coaches and those in charge of planning and developing training programs by predicting the levels and capabilities of the physical jumpers and the biomechanical aspects affecting the achievement of the competitors of the high jump event with strength games

\section{CONCLUSIONS}

There are varying degrees in the contribution of some physical abilities and biomechanical variables to the achievement of the high jump for young jumpers.

The predictive equation measures the achievement of the high jump in terms of some special physical abilities and the biomechanical variables most associated with achievement for young jumpers.

\section{Recommendations}

The necessity to use the proposed predictive equation to know the level of achievement of young hoppers by coaches to deal with the correct planning of training programs.

Familiarity with the percentage of the contribution of physical abilities and biomechanical variables for achieving the effectiveness of the high jump.

\section{REFERENCES}

Abdul Karim, S., \& Al-Mafraji, K. (2010). Theoretical and Scientific Foundations of Athletics for the Faculties of Physical Education, Beirut: Al-Ghadeer for Modern Artistic Printing, p.174.

Al-Fadhli, S. (2010). Biomechanical Applications in Sports Training and Kinetic Performance, Baghdad: House of Books and Documents.

Dapena, J. (2000). The High Jump. In: Zatsiorsky,V.(ed), Biomechanics in sport, Oxford, Blackwell Science, P285-311. https://doi.org/10.1002/9780470693797.ch14

Galeriek Ulturistiky (2005). Bodybuilding Exercises, Database , USA, P 179. 
Gneiting, T. \& Katzfuss, M. (2014). Probabilistic Forecasting: Annual Review of Statistics and Its Application. https://doi.org/10.1146/annurev-statistics-062713-085831

Majed, A. (2016). The effect of ballistic exercises according to some biochemical variables for the stage of advancement in the special force and the achievement of the high jump for youth, Master Thesis: University of Baghdad, College of Physical Education and Sports Sciences for Girls, p.63.

Radwan, M. (2002). Methods of Measuring Physical Exercise in Sports, 2nd Edition, Cairo, Al-Kitab Center for Publishing, p. 24.

Tidow, G. (1993).Model technique analysis sheets .part VIII :The flop high jump .New Studies in Athletics, 8(1),p. 44. 